\title{
Smart tourism: foundations and developments
}

\author{
Ulrike Gretzel $^{1} \cdot$ Marianna Sigala $^{2} \cdot$ Zheng Xiang $^{3} \cdot$ Chulmo Koo $^{4}$
}

Received: 1 June 2015 / Accepted: 9 July 2015 /Published online: 1 August 2015

(C) Institute of Information Management, University of St. Gallen 2015

\begin{abstract}
Smart tourism is a new buzzword applied to describe the increasing reliance of tourism destinations, their industries and their tourists on emerging forms of ICT that allow for massive amounts of data to be transformed into value propositions. However, it remains ill-defined as a concept, which hinders its theoretical development. The paper defines smart tourism, sheds light on current smart tourism trends, and then lays out its technological and business foundations. This is followed by a brief discussion on the prospects and drawbacks of smart tourism. The paper further draws attention to the great need for research to inform smart tourism development and management.
\end{abstract}

Responsible Editor: Rainer Alt

Chulmo Koo

helmetgu@khu.ac.kr

Ulrike Gretzel

u.gretzel@business.uq.edu.au

Marianna Sigala

m.sigala@aegean.gr

Zheng Xiang

philxz@vt.edu

1 UQ Business School, University of Queensland, Sir Fred Schonell Dr., St.Lucia, QLD 4072, Queensland, Australia

2 University of South Australia, 101 Currie Street, Adelaide 5000, South Australia, Australia

3 Department of Hospitality and Tourism Management, Virginia Polytechnic Institute and State University, Blacksburg, VA 24061, USA

4 College of Hotel \& Tourism Management, Kyung Hee University, Kyunheedaero 26, Heogi-dong, Dongdaemun-gu, Seoul 130-701, South Korea
Keywords Smart tourism - Smart technology · Smart business ecosystems $\cdot$ Business models · Open innovation $\cdot \mathrm{Big}$ data $\cdot$ Internet of things

"Smart" has become a new buzzword to describe technological, economic and social developments fuelled by technologies that rely on sensors, big data, open data, new ways of connectivity and exchange of information (e.g., Internet of Things, RFID, and NFC) as well as abilities to infer and reason. Höjer and Wangel (2015) argue that it is not so much the individual technological advances but rather the interconnection, synchronization and concerted use of different technologies that constitutes smartness. Harrison et al. (2010) conceptualize smart as exploiting operational, near-real-time real-world data, integrating and sharing data, and using complex analytics, modelling, optimization and visualization to make better operational decisions. The term has been added to cities (smart city) to describe efforts aimed at using technologies innovatively to achieve resource optimization, effective and fair governance, sustainability and quality of life. In connection with physical infrastructure (e.g., smart home, smart factory), the focus is on blurring the lines between the physical and the digital and on fostering technology integration. Added to technologies (smart phone, smart card, smart TV, etc.), it describes multifunctionality and high levels of connectivity. In the context of markets/economies (smart economy), it refers to technologies supporting new forms of collaboration and value creation that lead to innovation, entrepreneurship and competitiveness.

In the context of tourism, smart is used to describe a complex amalgam of all of the above. There is incredible institutional support and in some instances even pressure to realize smart tourism. Especially in Asia, there have been concerted efforts to drive the smart tourism agenda forward. Governments in China and South Korea are heavily funding initiatives mostly focused 
on building the technological infrastructure that supports smart tourism (Hwang et al. 2015). In Europe, many of the smart tourism initiatives were born out of smart city projects and, as a consequence, smart tourism destinations are increasingly making an appearance in the European tourism landscape. The focus in Europe, however, is more on innovation and competitiveness and developing smart end-user applications that support enriched tourism experiences using already existing data combined and processed in new ways (Lamsfus et al. 2015; Boes et al. 2015a, b). In Australia, the emphasis is on smart governance and specifically open data. What governments universally recognize is the transformative power of smart technologies not only in terms of the economic potential but also the social and experiential dimensions.

Yet in practice "smart" has become a very fuzzy concept often used to drive specific political agendas and to sell technological solutions. This is especially true in the case of "smart tourism", where it is frequently used in the context of open data initiatives or for rather trivial projects such as promoting free wifi or the development of mobile applications. While these technologies and new approaches to data collection, management and sharing are important stepping stones in implementing smart tourism, they do not provide the full picture of what smart tourism encompasses. There is also a lack of definitional clarity: suddenly everything is smart. Further, as far as smart tourism is concerned, theory seems to lag behind the many government and industry-led projects. Academic work is largely focused on describing the phenomenon in the form of case studies (e.g., Boes et al. 2015a, b; Bakıc1 et al. 2013; Wang et al. 2013) or on discussing isolated technological developments (e.g., Huang and Chen 2015; Boes et al. 2015a, b) rather than on laying the theoretical foundations for its advancement and/or critique. It is therefore the aim of this paper to provide insights regarding our current understanding of what smart tourism is, and what it is not. In addition, it outlines research needs to be met in order to inform the future development of smart tourism.

\section{Defining smart tourism}

According to the UNWTO (2015), tourism is "a social, cultural and economic phenomenon which entails the movement of people to countries or places outside their usual environment for personal or business/professional purposes". Given the information-intensity of tourism and the resulting high dependence on information and communication technologies (ICTs) (Law et al. 2014; Koo et al. 2015; Werthner and Klein 1999; Benckendorff et al. 2014), it is not surprising to see the concept of "smart" being applied to phenomena that encompass tourism. In many ways, smart tourism can be seen as a logical progression from traditional tourism and more recently e-tourism in that the groundwork for the innovations and the technological orientation of the industry and the consumers were laid early with the extensive adoption of information and communication technologies (ICT) in tourism, for instance in the form of global distribution and central reservation systems, the integration of Webbased technologies that led to the emergence of e-Tourism (Buhalis 2003; Werthner and Ricci 2004). This developmental trajectory continued with the widespread adoption of social media (Sigala et al. 2012), and a move towards realizing mobile tourism in recognition of the high mobility of tourism information and of tourism consumers (Buhalis and Law 2008; Wang et al. 2012). However, smart tourism is certainly a distinct step in the evolution of ICT in tourism in that the physical and governance dimensions of tourism are entering the digital playing field, new levels of intelligence are achieved in tourism systems (Gretzel 2011), the fabric of the industry is yet again changed and the ways in which tourism experiences are created, exchanged, consumed and shared are fundamentally different.

Smart tourism involves multiple components and layers of smart that are supported by ICTs (Fig. 1). On one hand, it refers to Smart Destinations, which are special cases of smart cities: they apply smart city principles to urban or rural areas and not only consider residents but also tourists in their efforts to support mobility, resource availability and allocation, sustainability and quality of life/visits. Lopez de Avila (2015, n.p.) defines the smart tourism destination as:

an innovative tourist destination, built on an infrastructure of state-of-the-art technology guaranteeing the sustainable development of tourist areas, accessible to everyone, which facilitates the visitor's interaction with and integration into his or her surroundings, increases the quality of the experience at the destination, and improves residents' quality of life.

The key aspect of smart destinations is the integration of ICTs into physical infrastructure. Barcelona, for instance offers travellers interactive bus shelters that not only provide touristic information and bus arrival times but also USB ports for charging mobile devices. In addition, it makes bicycles available throughout the city and travellers can check their locations via a smartphone app, thereby fostering environmentally friendly transportation around the city (http://smartcity.ben.cat/en/ bicing.html). The city of Brisbane has recently mounted over 100 beacons onto points of interest to communicate information to tourists via a mobile app if they are within a certain radius of the location (http://goo.gl/QidSOC). Amsterdam uses beacons to let tourist signs translate themselves into different languages and the Amsterdam ArenA is testing sensors for better crowd management (http://amsterdamsmartcity.com/). Seoul invests heavily in providing free wi-fi as well as smart phones to tourists (http://www.visitseoul.net), Jeju Island in South Korea has just declared itself as a smart tourism hub that will use innovative technology for content delivery to tourists (https:// youtu.be/d3C7vS-IbAY) and Sunmoon Lake in Taiwan 


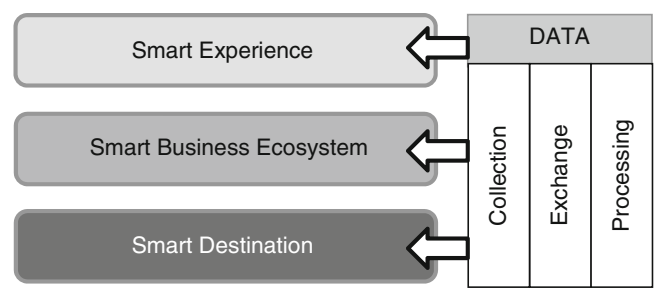

Fig. 1 Components and layers of smart tourism

provides location-based information on its tourist bus shuttles. Importantly, all these efforts are pieces of larger, coordinated efforts and strategic investments to foster innovation, quality of life and sustainability through enriching physical infrastructure with data within the context of specific destinations.

In addition to including a destination component, smart tourism is a social phenomenon arising from the convergence of ICTs with the tourism experience (Hunter et al. 2015). The smart experience component specifically focuses on technology-mediated tourism experiences and their enhancement through personalization, context-awareness and realtime monitoring (Buhalis and Amaranggana 2015). Neuhofer et al. (2015) identify information aggregation, ubiquitous connectedness and real-time synchronization as the major drivers of such smart tourism experiences. The smart tourism experience is efficient and rich in meaning. Tourists are active participants in its creation. They not only consume but also create, annotate or otherwise enhance data that constitutes the basis of the experience (e.g., by uploading photos to Instagram with destination-related hashtags or helping map toilets at destinations - http://www.nyrestroom.com/). The smart tourists and their digital selves (or data bodies) use smartphones to tap into information infrastructures provided at the destination or virtually in order to add value to their experiences.

The third component, Smart Business, refers to the complex business ecosystem that creates and supports the exchange of touristic resources and the co-creation of the tourism experience. Buhalis and Amaranggana (2014) describe the business component of smart tourism as being characterized by dynamically interconnected stakeholders, the digitalization of core business processes, and organizational agility. A distinct aspect of this smart business component is that it includes public-private collaboration to an extent that is unusual and results from governments becoming more open and technology-focused as providers of infrastructure and data. In addition, smart tourism recognizes that consumers can also create and offer value as well as monitor and therefore take on business or governance roles.

Importantly, smart tourism spans three layers across these three components: a smart information layer that aims at collecting data; a smart exchange layer that supports interconnectivity; and, a smart processing layer that is responsible for the analysis, visualization, integration and intelligent use of data (Tu and Liu 2014).

Based on these considerations, smart tourism is defined as tourism supported by integrated efforts at a destination to collect and aggregate/harness data derived from physical infrastructure, social connections, government/organizational sources and human bodies/minds in combination with the use of advanced technologies to transform that data into on-site experiences and business value-propositions with a clear focus on efficiency, sustainability and experience enrichment. Its main differences from e-tourism following the above descriptions and definition are further elaborated in Table 1.

\section{Technological foundations of smart tourism}

ICT is, undoubtedly, key to the conceptualization as well as development of smart tourism. While the notion of smart tourism became popular only recently among academics and practitioners, ICT with the ability to support tourism in an intelligent way has been discussed, developed, and envisioned for quite a long time (Gretzel 2011). Smart ICT is expected to be able to comprehend, to profit from experience, to acquire and retain knowledge, and to respond quickly and successfully to a new situation (Rudas and Fodor 2008). Within a smart tourism setting, this kind of technology is the key component of information systems that promise to supply tourism consumers and service providers with more relevant information, better decision support, greater mobility, and, ultimately, more enjoyable tourism experiences (Gretzel 2011; Werthner 2003; Sigala and Chalkiti 2014). These smart systems include a wide range of technologies in direct support of tourism such as decision support systems and the more recent recommender systems, context-aware systems, autonomous agents searching and mining Web sources, ambient intelligence, as well as systems that create augmented realities (Fesenmaier et al. 2006; Lamsfus et al. 2014; Venturini and Ricci 2006).

With the focus on the traveler as the user of these systems, these systems aim to support travelers by: 1) anticipating user needs based upon a variety of factors, and making recommendations with respect to the choice of context-specific consumption activities such as points of interest, dining and recreation; 2) enhancing travelers' on-site experiences by offering rich information, location-based and customized, interactive services; and 3) enabling travelers to share their travel experiences so that they help other travelers in their decision making process, revive and reinforce their travel experiences as well as construct their self-image and status on social networks. From the industry perspective, the emphasis is on the potential contributions of these smart systems in terms of process automation, efficiency gains, new product development, demand forecasting, crisis management, and value co-creation (Werthner 2003; Wöber 2003; Sigala 2012a and b; Yoo et al. 2015). Although these systems can be characterized as heterogeneous, distributed, and sometimes even fragmented, the overarching goal of developing these systems should be open, scalable, and cooperative, enabling full autonomy of the respective participants of the 
Table 1 Smart Tourism vs. e-Tourism

\begin{tabular}{lll}
\hline & e-Tourism & Smart Tourism \\
\hline Sphere & digital & bridging digital \& physical \\
Core technology & websites & sensors \& smartphones \\
Travel phase & pre- \& post-travel & during trip \\
Lifeblood & information & big data \\
Paradigm & interactivity & technology-mediated co-creation \\
Structure & value chain/intermediaries & ecosystem \\
Exchange & B2B, B2C, C2C & public-private-consumer collaboration \\
\hline
\end{tabular}

industry as well as supporting the entire tourist experience and all business phases (Staab and Werthner 2002).

In smart tourism, technology is seen as an infrastructure, rather than as individual information systems, and encompasses a variety of smart computing technologies that integrate hardware, software, and network technologies to provide real-time awareness of the real world and advanced analytics to help people make more intelligent decisions about alternatives, as well as actions that will optimize business processes and business performances (Washburn et al. 2010). Today, the widespread use of mobile devices, especially of the smartphone and its numerous apps, signifies an era of unprecedented connectivity and ubiquitous access to the Internet (Wang and Xiang 2012). Many technological developments that support mobile access, such as Cloud Computing and End-User Internet Service Systems are thus instrumental to facilitating smart tourism goals.

As indicated in Table 1, bridging the physical world with the digital realm is a central concern for smart tourism development. The increasing use of iBeacon technology in tourism ensures a first step in this direction in that it allows smart phones to react to signals from the physical world in order to support ambient context identification (see www. ibeaconinsider.com for an elaboration). However, ultimately, realizing the Internet of Things (IoT) will be crucial for creating the desired pervasive, "smart" technological environment that encompasses connected physical and digital infrastructures. Remaining largely a vision at this stage, the Internet of Things has the potential to rapidly become a new reality as a technological infrastructure (Atzori et al. 2010). It has been identified as an important foundation for the services to be provided by smart tourism cities (Guo et al. 2014; Perera et al. 2014). The basic idea of the IoT is the pervasive presence around us of a variety of objects such as Radio-Frequency-Identification (RFID) tags, sensors, actuators, mobile devices, etc., which are able to interact with each other and cooperate with their neighboring objects to achieve common goals (Want et al. 2015). These objects are connected to the Internet which consequently bridges the gap between the real world and the digital realm. Hence, the IoT enables the development of various platforms able to transmit a wide range and various types of data using participatory sensing systems (Gutiérrez, et al. 2013). Importantly, the emergence of the IoT will provide a shift in service provision, moving from the current vision of always-on services, typical in the Web era, to always-responsive situated services, built and composed at run-time to respond to a specific need and able to account for the user's context. Thus, it is predicted that the Internet will soon realize the vision long dreamed of - a seamless fabric of classic networks and networked objects which can be identified, located, monitored, and managed anytime and anyplace. Content and services will all be around us, persistently available, creating conditions for new applications and enabling new ways of working, interacting, entertainment, and living (Miorandi et al. 2012).

The innovations driven by the IoT have important implications for tourism development because travel involves movement through time and space and this "smart" environment will grow to be aware of, and be able to address, the traveler's contextual needs in a pervasive yet non-intrusive way. For example, sensors embedded in tourist attractions will enable tourism service providers to track tourists' locations and their consumption behavior so that location-based services could be offered. Wearable technologies such as smart watches play an important role in this as well as they not only collect data through their sensors and cameras but also communicate with the network and potentially the IoT and support high levels of connectivity without interfering with the experience. At the management level, this type of system can be employed to control visitor numbers within specific tourism sites by using a variety of sensors with each site's carrying capacity as a benchmark. The social dimensions also have to be recognized as smart objects embedded in the environment may automatically trigger the transmission of messages to family and friends to enable them to know what we are doing or what we have done in the past, such as moving from one site to another or meeting some common friends. Within a social setting we may think of the IoT as a platform that generates information about 'events' of people and places which is gathered and uploaded to provide information about travelers within their social networking sites. As such, the technological factor of smart tourism is multidimensional consisting of the ubiquitous infrastructure, more mobile and context-aware information systems, and the increasingly complex and dynamic connectivity that supports real-time interactions not only with one's physical environment but also the community and society at large, directly or indirectly related to the traveler. 
Smart tourism also clearly rests on the ability to not only collect enormous amounts of data but to intelligently store, process, combine, analyze and use big data to inform business innovation, operations and services. Numerous technologies support big data creation and, in the context of smart tourism, they are often the ones put into the limelight. However, a lot of innovation is also happening in the other big data areas with the ultimate goal of deriving intelligence from massive amounts of data, which is what is at the core of smart tourism initiatives.

\section{Business foundations of smart tourism}

ICT tools and applications have enabled tourism firms to become 'smarter' in how to increase their performance and competitiveness by (hyper)-automating, informating and transforming their business functions and processes such as marketing, procurement/supply chain management, human resource management, and customer service and management (Sigala and Marinidis 2012). However, the business impact of ICT is not limited to solely functional effects. ICT have also an instrumental role in driving institutional and structural market changes in the tourism industry. To survive, traditional tourism firms have to redefine their business model and the way they propose to create customer value. Indeed, the numerous definitions of a business model converge to reflect "the design or architecture of the value creation, delivery and capture mechanisms" (Teece 2010: 191). By introducing new business models, firms develop new markets (Callon and Muniesa 2005; MacKenzie and Millo 2003; Pollock and Williams 2009; Inversini and Masiero 2014; Storbacka and Nenonen 2011). Sigala (2015) describes smart tourism as changing all or some of the following five market elements: exchange object, market actors, market structure, market institutions, and market practices. Morabito (2015) suggests that operating in a big data driven, smart environment affects all nine elements of business models in fundamental ways: 1) customer segments; 2) value propositions; 3) channels; 4) customer relationships; 5) revenue streams; 6) key resources; 7) key activities; 8) key partnerships; and, 9) cost structure. To define their business model, firms should therefore determine the following design elements: customer value creation, the actor's earnings logic, value network of the actor, resources and capabilities that the actor has, and strategic decisions that the actor makes (Nenonen and Storbacka 2010). However, what the actual smart tourism business models are has yet to be determined. Most smart tourism initiatives are currently in development and heavily subsidized by government. Indeed, while new governance models for public services in smart cities have been presented in the literature (Anttiroiko et al. 2014), theoretical development of business models suitable for smart tourism is lacking. Morabito (2015) goes as far as suggesting that smart tourism might mean profoundly questioning the way we think about business models and their importance for strategy. Literature in the fields of open innovation, service-dominant-logic (SDL) and service science provides the theoretical underpinnings for management approaches that firms can adopt to identify, address and exploit the opportunities, challenges and affordances of smart tourism and to re-define their business models and sustain competitiveness (Schmidt_Rauch and Schwabe 2014).

Open innovation is based on the assumption that an organisation cannot just rely on its own resources, but has to engage with partners in order to innovate (Dahlander and Gann 2010; West and Gallagher 2006). To that end, tourism firms have to collaborate with stakeholders beyond their organizational borders in order to source and exchange resources for value co-creation.

According to service science and SDL, value co-creation takes place inside wider service ecosystems (Anttiroiko et al. 2014). However, although a functioning service ecosystem is seen as a major prerequisite for enabling the co-creation of customer experiences (Vargo and Lusch 2014), little is still known about how firms can actually construct and continuously manage such service ecosystems. Vargo et al. (2008) and Spohrer et al. (2007) described a service ecosystem as a spontaneously sensing and responding spatial and temporal structure of largely loosely-coupled value-proposing social and economic actors interacting through institutions and technology, to: (1) co-produce service offerings, (2) exchange service offerings and resources (3) co-create value. This corresponds to Buhalis and Amaranggana's (2014) notion of dynamically interconnected smart tourism stakeholders and Van Heck and Vervest's (2007) definition of smart business networks that allow for "plug and play" scenarios to seize emerging value creation opportunities. Social media and internet tools are instrumental in enabling firms to develop such dynamic connections, as technologies enable them to network with others and to seamlessly exchange resources. SchmidtRauch and Schwabe (2014) discuss the importance of mobile technology for co-creation in the smart tourism ecosystem, proposing that it opens up communication channels and allows for a shared representation of the solution space in situ. Resources that actors may possess and exchange in a smart tourism ecosystem can relate to the following types: tangible or intangible resources (e.g., tools, software, and information); human resources (e.g., skills, knowledge, and virtual communities); and relational ones (e.g., relations to partners and suppliers, and network membership). In a smart service ecosystem, any stakeholder is an actor aiming to interact and exchange resources with other actors for value co-creation. In this vein, labels and roles assigned to players like travelers, firms and intermediaries are not valid anymore (Vargo and Lusch 2008). In a smart tourism ecosystem, any type of stakeholder can become a producer, consumer, intermediary etc. depending on resources and connections rather than pre- 
defined roles (Gretzel et al. 2015). This means producer-client relationships have to be redefined and new approaches to cooperation in production, delivery and consumption of services have to be developed (Anttiroiko et al. 2014).

Yoo et al. (2015) described the ways and strategies adopted by TripAdvisor for constructing its service ecosystem by identifying its various stakeholders, the types of resources that are being exchanged and the type of value that is co-created from these interactions. The paper highlights the need of tourism firms to adopt open information systems and business models, as they enable them to manage their smart tourism ecosystems in a dynamic way and support 'plugging and playing' stakeholders ad hoc depending on what resources need to be exchanged. This is the case because open business ecosystems enable actors to co-create 'value-in-context' by accessing, mixing and matching, exchanging, adapting and integrating resources in many different and flexible ways depending on the consumption situation.

In smart tourism, business builds on an extensive "infostructure" and the big data that sustains it is to a large extent either actively (e.g., uploaded onto social media) or implicitly (through sensors on mobile or wearable devices) provided by consumers. Indeed the very concept of smart tourism is very much based on the assumption that data is willingly shared by these consumers. Smart tourism business relies on an abundance of free information and on access to open technological platforms to be transformed into value propositions. At the same time, smart tourism infostructure can lead to new information asymmetries that can be commercially exploited (Tachizawa et al. 2015). Economic power in smart tourism is without doubt derived from control over information sources and flows. It is also important to recognize that value not only emerges from ownership but increasingly from access to infrastructure or data. Therefore, beyond traditional notions of value creation, businesses seeking to operate within smart tourism environments have to consider "value-in-use" (Bick et al. 2012), referring to value creation through use of data/technology/infrastructure rather than ownership and beyond individual exchanges.

Anttiroiko et al. (2014) argue that smart service ecosystems require new alliances to share risk, circulate knowledge, and extend or reformulate value chains/neworks and that they constitute an environment in which there is great competitive pressure to be cost-effective and innovative in (re)configuring services. Tachizawa et al. (2015) present possible implications of smart cities on business network structures and governance mechanisms, suggesting that the resulting smart ecosystems are complex with high transaction costs that probably favor informal governance. Similarly, Anttiroiko et al (2014) describe the necessary creative mutuality and cooperation in these systems as more difficult to manage than traditional competitive rivalry. On the other hand, greater complexity in network structures might open up structural holes that can be exploited by businesses. These assumptions need to be further explored/validated to build solid foundations for striving smart tourism businesses.

\section{Discussion and implications for research}

Research in the area of smart tourism remains very limited and mostly provides case studies of existing initiatives. It also largely focuses on the consumer-perspective and has adopted a very optimistic and uncritical stance. The following discussion points out several key research areas that have to be addressed in order to ensure the successful realization of smart tourism goals.

Data lies at the core of all smart tourism activities. Privacy is therefore an obvious concern in the context of smart tourism. Especially location-based services, while extremely useful for tourists, also make consumers vulnerable. Privacy in tourism is a special case as relationships with providers and therefore their apps/services are typically short-lived, which limits trust-building. Also, the need for information is so great, that tourists might be easily persuaded to forego privacy (Anuar and Gretzel 2011). The digital footprint of a smart tourist is huge and opportunities for mining the digital traces left while on vacation or traveling for business are manifold. Smart tourism is becoming a big contributor to and benefactor of the "sensor society" (Andrejevic and Burdon 2015) that is characterized by ubiquitous, always-on data capture. With it come concerns of being able to identify individuals out of large collections of supposedly anonymous data, automatic capture of data for no concrete purpose, and surveillance under the disguise of service provision. Smart tourism raises big issues with respect to information governance (Tallon 2013) and correctly deriving the value of information. The current assumption is that all information is extremely valuable to businesses and will be freely provided by the smart tourists who seek enriched tourism experiences. Data is mindlessly captured and storage/retrieval/information management costs are not calculated. While smart city concept implementations have forced governments to carefully think about what data they have and in what way it could be made useful, such efforts are not necessarily taking place in businesses. Therefore, a major area of research necessary in the context of smart tourism is information governance and privacy, with particular questions relating to determining the value of information and ensuring safety and security in rather open and ubiquitous info-structures.

Another issue increasingly discussed in the context of smart tourism is the extreme technology-dependence. This has clear implications in terms of a widening digital divide (Minghetti and Buhalis 2010) for those without smartphones and destinations that cannot afford to build smart tourism infostructures. But the problem is not only access or affordability: recent developments in the smartwatch market suggest 
that consumers are only reluctantly adopting this wearable technology (Forbes 2015). Also, when inspected, this ICT dependence reveals other issues, namely information overload, lack of serendipity that is often essential to meaningful tourism experiences, and an increasing desire to at least escape technology when on vacation (Gretzel 2010). While research is already being conducted on how technology enhances tourism experiences, there is a clear lack of research focusing on potential drawbacks of too much mediation. What is clearly needed is a more critical perspective on smart tourism experiences, more information on psychological and health risks of constant bombardment with data by context-aware systems and insights regarding consumer attitudes towards the various aspects of smart tourism, including their willingness to cocreate and their enjoyment of such processes and the actual dimensions of "value-in-use" derived by consumers.

Needing to unlock the power of big data for translation into smart tourism services also raises the issue of human and artificial intelligence necessary to do so. Tourism is not currently a sector that attracts a lot of knowledge workers. It also struggles notoriously with innovation deficiencies despite its strong reliance on ICT (Hjalager 2002). Human resources issues with respect to smart tourism are not typically discussed. Further, smart tourism has a very utopian view of happy collaboration among various actors and a self-regulating ecosystem in which value will be sustainably produced. In addition, as mentioned above, what business models can and should be adopted in this context remains a mystery. Therefore, more research from an organizational and management perspective is needed, as well has conceptual and empirical investigations into the economics of smart tourism.
Despite these concerns, smart tourism is an incredibly promising scenario that results in more convenient, safe, exciting and sustainable living spaces for both residents and tourists, more personalized and therefore more relevant tourism experiences, and even greater opportunities for new services, business models and markets to emerge as a result of more flexible structures and different perspectives on value creation. Werthner et al. (2015) have recently published a research manifesto that outlines the many layers on which tourism and ICT-related research needs to make significant contributions. From looking at human-computer interaction issues to social dynamics, market structures and industry value chains to informing policy and governance, smart tourismrelated research has to fill many gaps to be able to critically inform smart tourism initiatives. Research in connection with design science is further needed to explore the new value creation opportunities supplied by smart tourism and translate them into working ICTs. Many of the pillars of the emerging smart tourism economy like Uber or AirBnB are based on simple technological platforms that take advantage of existing technologies to exploit a distinct market niche. These technology-market combinations need to be systematically explored and mapped to support innovation activities. It also becomes very clear that advances in semantic technologies and artificial intelligence are needed to really exploit the various data layers. Since sustainability is a major concern, the true costs of smart tourism (e.g., energy consumption, ewaste, etc.) have to be estimated. Finally, whether smart tourists are actually having better experiences has yet to be empirically investigated. Table 2 summarizes the main research areas identified.
Table 2 Smart tourism research agenda

\begin{tabular}{ll}
\hline Smart Tourism Aspect & Research Topics \\
\hline Consumption & Privacy concerns \\
& Attitudes toward co-creation \\
& Value derived \\
& Physiological consequences of ubiquitous connectivity \\
& Need/desire for escape from technology \\
& Technology access \\
& Value of data/information \\
& Exploitable technology-market combinations \\
Service Provision & Suitable business models \\
& Innovation capacity \\
& Human resources implications \\
& Collaboration/coordination mechanisms \\
Facilitation & Market dynamics \\
& Information governance \\
& Infrastructure requirements \\
& Social and environmental cost \\
& Artificial intelligence
\end{tabular}




\section{Conclusion}

This paper attempted to provide definitional clarity and an overview of the basic assumptions underlying the smart tourism concept. It identified smart destinations, smart business ecosystems and smart experiences as the three basic components supported by layers of data creation, processing and exchange. In doing so it established smart tourism as distinct from general e-tourism not only in the core technologies of which it takes advantage but also in the approaches to creating enhanced at-destination experiences. The paper highlighted the strong practical and theoretical grounding in smart cityrelated conceptualizations and the resulting focus on public service models at the expense of comprehensive and systematic exploration of its business opportunities and implications. It also revealed a lack of critical literature that scrutinizes smart tourism assumptions and questioned its feasibility and positive experiential, economic and societal impacts. The paper proposed a research agenda, which is far from being comprehensive; rather, it sought to emphasize the currently most overlooked gaps in understanding the potential of smart tourism and its possible drawbacks.

Smart tourism development is already under way. In many ways it naturally evolves from the extensive uptake of technology in tourism. However, the systematic and widespread coordination and sharing as well as exploitation of touristic data for value creation is still in its infancy. Smart tourism initiatives around the world are seeking to build viable smart tourism ecosystems (Gretzel et al. 2015) but the complexity of the sector makes it extremely difficult to go beyond very specific platform-, technology- or service-specific innovations. Yet, the technology push in the direction of smart tourism is immense and it is expected that tourism will provide the backdrop for pioneering many of these smart technologies.

Acknowledgments This work was supported by the National Research Foundation of Korea Grant funded by the Korean Government (NRF2013S1A3A2043345).

\section{References}

Andrejevic, M., \& Burdon, M. (2015). Defining the sensor society. Television and New Media, 16(1), 19-36.

Anttiroiko, A. V., Valkama, P., \& Bailey, S. J. (2014). Smart cities in the new service economy: building platforms for smart services. AI and Society, 29(3), 323-334.

Anuar, F. I. \& Gretzel, U. (2011). Privacy Concerns in the Context of Location Based Services for Tourism. ENTER 2011 Conference, Innsbruck, Austria, January 26-28, 2011. Accessed online (March 1, 2015) at http://ertr.tamu.edu/enter-2011-short-papers/.

Atzori, L., Iera, A., \& Morabito, G. (2010). The internet of things: a survey. Computer Networks, 54(15), 2787-2805.

Bakıc1, T., Almirall, E., \& Wareham, J. (2013). A smart city initiative: the case of Barcelona. Journal of the Knowledge Economy, $4(2), 135-148$
Benckendorff, P., Sheldon, P., \& Fesenmaier, D. R. (2014). Tourism information technology. Oxford: CAB International.

Bick, M., Bruns, K., Sievert, J., \& Jacob, F. (2012). Value-in-use of mobile technologies. In Back, A., Bick, M., Breunig, M. Pousttchi, K., Thiesse, F. (ed.s) MMS 2012, pp. 56-67. Bonn, Germany: Köllen Druck \& Verlag.

Boes, K., Borde, L., \& Egger, R. (2015a). The Acceptance of NFC Smart Posters in Tourism. In I. Tussyadiah \& A. Inversini (Eds.), Information and Communication Technologies in Tourism 2015 (pp. 435-448). Heidelberg: Springer.

Boes, K., Buhalis, D., \& Inversini, A. (2015b). Conceptualising Smart Tourism Destination Dimensions. In I. Tussyadiah \& A. Inversini (Eds.), Information and Communication Technologies in Tourism 2015 (pp. 391-403). Heidelberg: Springer.

Buhalis, D. (2003). eTourism: Information technology for strategic tourism management. Pearson Education.

Buhalis, D., \& Amaranggana, A. (2014). Smart Tourism Destinations. In Z. Xiang \& I. Tussyadiah (Eds.), Information and Communication Technologies in Tourism 2014 (pp. 553-564). Heidelberg: Springer.

Buhalis, D., \& Amaranggana, A. (2015). Smart Tourism Destinations: Enhancing Tourism Experience Through Personalisation of Services. In I. Tussyadiah \& A. Inversini (Eds.), Information and Communication Technologies in Tourism 2015 (pp. 377-389). Heidelberg: Springer.

Buhalis, D., \& Law, R. (2008). Progress in information technology and tourism management: 20 years on and 10 years after the InternetThe state of eTourism research. Tourism Management, 29(4), 609623.

Callon, M., \& Muniesa, F. (2005). Economic markets as calculative collective devices. Organization Studies, 26(8), 1229-1250.

Dahlander, L., \& Gann, D. M. (2010). How open is innovation? Research Policy, 39(6), 699-709.

Lopez de Avila, A. (2015). Smart Destinations: XXI Century Tourism. Presented at the ENTER2015 Conference on Information and Communication Technologies in Tourism, Lugano, Switzerland, February 4-6, 2015.

Fesenmaier, D., Werthner, H., \& Wöber, K. (2006). Destination Recommendation Systems: Behavioral Foundations and Applications. Cambridge: CAB International.

Forbes (2015). Apple Watch Sales Aren't Looking So Hot. Accessed online (July 4, 2015) at: http://www.forbes.com/sites/aarontilley/ 2015/07/01/apple-watch-sales-arent-looking-so-hot/.

Gretzel, U. (2010). Travel in the Network: Redirected Gazes, Ubiquitous Connections and New Frontiers. In M. Levina \& G. Kien (Eds.), Post-global Network and Everyday Life (pp. 41-58). New York: Peter Lang.

Gretzel, U. (2011). Intelligent systems in tourism: a social science perspective. Annals of Tourism Research, 38(3), 757-779.

Gretzel, U., Werthner, H., Koo, C., \& Lamsfus, C. (2015). Conceptual Foundations for Understanding Smart Tourism Ecosystems. Computers in Human Behavior, forthcoming.

Guo, Y., Liu, H., \& Chai, Y. (2014). The embedding convergence of smart cities and tourism internet of things in China: an advance perspective. Advances in Hospitality and Tourism Research, 2(1), 54-69.

Gutiérrez, V., Galache, J. A., Sánchez, L., Muñoz, L., Hernández-Muñoz, J. M., Fernandes, J., \& Presser, M. (2013). SmartSantander: Internet of things research and innovation through citizen participation. In A. Galis \& A. Gavras (Eds.), The Future Internet (pp. 173-186). Heidelberg: Springer.

Harrison, C., Eckman, B., Hamilton, R., Hartswick, P., Kalagnanam, J., Paraszczak, J., \& Williams, P. (2010). Foundations for smarter cities. IBM Journal of Research and Development, 54(4), 1-16.

Hjalager, A. M. (2002). Repairing innovation defectiveness in tourism. Tourism Management, 23(5), 465-474.

Höjer, M., \& Wangel, J. (2015). Smart Sustainable Cities: Definition and Challenges. In L. M. Hilty \& B. Aebischer (Eds.), ICT Innovations 
for Sustainability, Advances in Intelligent Systems and Computing (pp. 333-349). New York: Springer.

Huang, C. M., \& Chen, S. C. (2015). Smart tourism: exploring historical, cultural, and delicacy scenic spots using visual-based image search technology. Applied Mechanics and Materials, 764, 1265-1269.

Hunter, W. C., Chung, N., Gretzel, U., \& Koo, C. (2015). Constructivist research in smart tourism. Asia Pacific Journal of Information Systems, 25(1), 105-120.

Hwang, J., Park, H. Y., \& Hunter, W. C. (2015). Constructivism in smart tourism research: Seoul destination image. Asia Pacific Journal of Information Systems, 25(1), 163-178.

Inversini, A., \& Masiero, L. (2014). Selling rooms online: the use of social media and online travel agents. International Journal of Contemporary Hospitality Management, 26(2), 272-292.

Koo, C., Gretzel, U., Hunter, W. C., \& Chung, N. (2015). The role of IT in tourism. Asia Pacific Journal of Information Systems, 25(1), 99-104.

Lamsfus, C., Wang, D., Alzua-Sorzabal, A., \& Xiang, Z. (2014). Going Mobile Defining Context for On-the-Go Travelers. Journal of Travel Research, DOI:0047287514538839.

Lamsfus, C., Martín, D., Alzua-Sorzabal, A., \& Torres-Manzanera, E. (2015). Smart tourism destinations: An extended conception of smart cities focusing on human mobility. In I. Tussyadiah \& A. Inversini (Eds.), Information and Communication Technologies in Tourism 2015 (pp. 363-375). Heidelberg, Germany: Springer.

Law, R., Buhalis, D., \& Cobanoglu, C. (2014). Progress on information and communication technologies in hospitality and tourism. International Journal of Contemporary Hospitality Management, 26(5), 727-750.

MacKenzie, D., \& Millo, Y. (2003). Constructing a market, performing theory: the historical sociology of a financial derivatives exchange. American Journal of Sociology, 109, 107-145.

Minghetti, V., \& Buhalis, D. (2010). Digital divide in tourism. Journal of Travel Research, 49(3), 267-281.

Miorandi, D., Sicari, S., De Pellegrini, F., \& Chlamtac, I. (2012). Internet of things: vision, applications and research challenges. Ad Hoc Networks, 10(7), 1497-1516.

Morabito, V. (2015). Big Data and Analytics. Berlin: Springer International Publishing.

Nenonen, S., \& Storbacka, K. (2010). Business model design: conceptualizing networked value co-creation. International Journal of Quality and Service Sciences, 2(1), 43-59.

Neuhofer, B., Buhalis, D., \& Ladkin, A. (2015). Smart technologies for personalized experiences: a case study in the hospitality domain. Electronic Markets, forthcoming.

Perera, C., Zaslavsky, A., Christen, P., \& Georgakopoulos, D. (2014). Sensing as a service model for smart cities supported by internet of things. Transactions on Emerging Telecommunications Technologies, 25(1), 81-93.

Pollock, N., \& Williams, R. (2009). The sociology of a market analysis tool: how industry analysts sort vendors and organize markets. Information and Organization, 19(2), 129-151.

Rudas, I. J., \& Fodor, J. (2008). Intelligent systems. International Journal of Computers, Communication \& Control, III (Suppl.), 132-138.

Schmidt-Rauch, S., \& Schwabe, G. (2014). Designing for mobile value co-creation - the case of travel counselling. Electronic Markets, 24(1), 5-17.

Sigala, M. (2012a). Social media and crisis management in tourism: applications and implications for research. Information Technology and Tourism, 13(4), 269-283.

Sigala, M. (2012b). Social networks and customer involvement in New Service Development (NSD): the case of www.mystarbucksidea. com. International Journal of Contemporary Hospitality Management, 24(7), 966-990.
Sigala, M. (2015). From demand elasticity to market plasticity: A market approach for developing revenue management strategies in tourism. Journal of Travel and Tourism Marketing, forthcoming.

Sigala, M., \& Chalkiti, K. (2014). Investigating the exploitation of web 2.0 for knowledge management in the Greek tourism industry: an utilisation-importance analysis. Computers in Human Behavior, 30, $800-812$.

Sigala, M., \& Marinidis, D. (2012). Web map services in tourism: a framework exploring the organisational transformations and implications on business operations and models. International Journal of Business Information Systems, 9(4), 415-434.

Sigala, M., Christou, E., \& Gretzel, U. (Eds.). (2012). Social media in travel, tourism and hospitality: Theory, practice and cases. Ashgate Publishing, Ltd.

Spohrer, J., Maglio, P. P., Bailey, J., \& Gruhl, D. (2007). Steps toward a science of service systems,". Computer, 40(1), 71-77.

Staab, S., \& Werthner, H. (2002). Intelligent systems for tourism. IEEE Intelligent Systems, November/December, 2002, 53-55.

Storbacka, K., \& Nenonen, S. (2011). Scripting markets: from value propositions to market propositions. Industrial Marketing Management, 40, 255-266.

Tachizawa, E. M., Alvarez-Gil, M. J., \& Montes-Sancho, M. J. (2015). How "smart cities" will change supply chain management. Supply Chain Management: An International Journal, 20(3), 237-248.

Tallon, P. P. (2013). Corporate governance of big data: perspectives on value, risk, and cost. Computer, 46(6), 32-38.

Teece, D. J. (2010). Business models, business strategy and innovation. Long Range Planning, 43(2/3), 172-194.

Tu, Q. \& Liu, A. (2014). Framework of Smart Tourism Research and Related Progress in China. In International Conference on Management and Engineering (CME 2014), pp. 140-146. DEStech Publications.

UNWTO (2015). Understanding Tourism: Basic Glossary. Accessed online (May 25, 2015) at http://media.unwto.org/en/content/ understanding-tourism-basic-glossary.

Van Heck, E., \& Vervest, P. (2007). Smart business networks: how the network wins. Communications of the ACM, 50(6), 29-37.

Vargo, S. L., \& Lusch, R. F. (2008). Service-dominant logic: continuing the evolution. Journal of the Academy of Marketing Science, 36(1), 1-10.

Vargo, S. L., \& Lusch, R. F. (2014). Inversions of service-dominant logic. Marketing Theory, 14(3), 239-248.

Vargo, S. L., Maglio, P. P., \& Akaka, M. A. (2008). On value and value co-creation: a service systems and service logic perspective. European Management Journal, 26(3), 145-152.

Venturini, A., \& Ricci, F. (2006). Applying Trip@dvice Recommendation Technology to www.visiteurope.com. Frontiers in Artificial Intelligence and Applications, 141, 607.

Wang, D., \& Xiang, Z. (2012). The new landscape of travel: A comprehensive analysis of smartphone apps. In M. Fuchs, F. Ricci, \& L. Cantoni (Eds.), Information and Communication Technologies in Tourism 2012 (pp. 308-319). Wien: Springer.

Wang, D., Park, S., \& Fesenmaier, D. (2012). The role of smartphones in mediating the tourism experience. Journal of Travel Research, 51(4), 371-387.

Wang, D., Li, X. R., \& Li, Y. (2013). China's "smart tourism destination" initiative: a taste of the service-dominant logic. Journal of Destination Marketing and Management, 2(2), 59-61.

Want, R., Schilit, B. N., \& Jenson, S. (2015). Enabling the Internet of Things. Computer, 1, 28-35.

Washburn, D., Sindhu, U., Balaouras, S., Dines, R. A., Hayes, N., \& Nelson, L. E. (2010). Helping CIOs Understand "Smart City" Initiatives. Accessed online (March 1, 2015) at: http://www. uwforum.org/upload/board/forrester help cios smart city.pdf.

Werthner, H. (2003). Intelligent Systems in Travel and Tourism. In: Proceedings of International Joint Conference on Artificial Intelligence (IJCAI 2003), Acapulco, Mexico, August 9-15, 2003, 
pp. 1620-1625. Accessed online (February 15, 2015) at http://ijcai. org/Past $\% 20$ Proceedings/IJCAI-2003/PDF/286.pdf.

Werthner, H., \& Klein, S. (1999). Information technology and tourism: a challenging relationship. Vienna: Springer.

Werthner, H., \& Ricci, F. (2004). E-Commerce and Tourism. Communications of the ACM, 47(12), 101-105.

Werthner, H., Alzua-Sorzabal, A., Cantoni, L., Dickinger, A., Gretzel, U., Jannach, D., Neidhardt, J., Pröll, B., Ricci, F., Scaglione, M., Stangl, B., Stock, O., \& Zanker, M. (2015). Future research issues in IT and tourism. Journal for Information Technology and Tourism, forthcoming.. doi:10.1007/s40558-014-0021-9.
West, J., \& Gallagher, S. (2006). Challenges of open innovation: the paradox of firm investment in open source software. $R \& D$ Management, 36(3), 319-331.

Wöber, K. W. (2003). Information supply in tourism management by marketing decision support systems. Tourism Management, 24(3), 241-255.

Yoo, K.-H., Sigala, M., \& Gretzel, U. (2015). Exploring TripAdvisor. In R. Egger, I. Gula, \& D. Walcher (Eds.), Open Tourism Open Innovation, Crowdsourcing and Collaborative Consumption challenging the tourism industry. Heidelberg: Springer Verlag. 